\title{
Investment priorities and investment potential of various infrastructure facilities of the city
}

\author{
Alexandra Radushinskaya ${ }^{1 *}$, Maria Pushkina $^{l}$, Anna Antonova $^{2}$, Svetlana Morozova ${ }^{1}$, \\ Galina Dyakova ${ }^{3}$ and Elena Gaganova ${ }^{3}$ \\ ${ }^{1}$ St. Petersburg State University, 191104, 62, st. Chaykovskogo, St. Petersburg, Russia \\ ${ }^{2}$ Saint Petersburg Polytechnic University of Peter the Great, Institute of Industrial Management, \\ Economics and Trade, High School of Trade and Service, 195251, 29/3, st. Politekhnicheskaya, St. \\ Petersburg, Russia \\ ${ }^{3}$ Russian New University ROSNOU, 129300, 22, Radio str., Moscow, Russia \\ ${ }^{4}$ Russia State university of management, 109542, 99, Ryazansky Avenue, Moscow, Russia
}

\begin{abstract}
The article discusses the investment strategies of university students in relation to the infrastructure of the city, the characteristics of which were evaluated from the point of view of respondents as suitable / not suitable in order to plan their own life in this city. It was proposed to evaluate the investment priorities and investment potential of various infrastructure facilities of the city and aspects of its life. Quantitative and qualitative research was carried out in relation to the investment priorities of the objects: transport infrastructure, urban amenities, urban recreation areas, cultural, art and patriotism development objects, sports facilities and leisure facilities on the example of St. Petersburg. As part of the study, students were also asked to assess the potential willingness to invest in the future as owners or managers of enterprises. The article analyses the significance of a number of urban projects for environmental planning for the development of the territory, including the elements of the Lakhta Center public space in St. Petersburg.
\end{abstract}

\section{Introduction}

Investment processes are of high importance, both at the country level and at the level of regions and individual enterprises, since thanks to the investment it is possible to develop a comfortable living environment, production capacities and infrastructure, create new jobs, attract the best specialists to the region and tourists, which ultimately has a significant impact on improving the quality of life of residents of this territory.

The investment attractiveness of the territory is determined by many factors widely studied in the modern scientific literature [1,2,3 and others]. We decided to conduct a study of the attractiveness of the place of current residence and work among students of St. Petersburg, which they would associate with the investment potential and attractiveness of the territory.

\footnotetext{
*Corresponding author: aleigrad@gmail.com
} 
Students are a social stratum that flexibly absorbs current trends and takes them into account when planning for the future. Many of them will play a significant role in determining investment expectations and "moods" of the city population, making investment decisions at various levels - from large companies to the family budget, which will affect the overall attractiveness of the territory.

The attractiveness of a place to live and work for a modern person plays a significant role. The results of one of recent studies on the importance of the city as a factor affecting the realization of human needs, found that in the hierarchy of conditions, he occupies the fourth position, second only to the personal efforts of the person (1st place), the presence of social connections, the impact of family and friends (2nd and 3rd places respectively) [4].

The composition of the attractiveness factors of the territory is currently multilaterally studied and includes indicators that influence decision-making by the local administration, investors, representatives of the creative class (living and working on the territory), tourists (visiting the territory), and residents (Table 1).

Table 1. Factors of attractiveness of the territory

\begin{tabular}{|c|c|}
\hline Name and description of the factor & Attractiveness meters \\
\hline $\begin{array}{l}\text { 1. Geographical attractiveness is a feature } \\
\text { of the territory, characterized by its spatial } \\
\text { position. }\end{array}$ & $\begin{array}{l}\text { size of the territory; climatic conditions; } \\
\text { natural resources (mineral resources and } \\
\text { resources of the biosphere), etc. }\end{array}$ \\
\hline $\begin{array}{l}\text { 2. Economic attractiveness is the ability of } \\
\text { the territory to ensure its sustainable } \\
\text { financial situation }\end{array}$ & $\begin{array}{l}\text { profitability of enterprises and organizations } \\
\text { of the territory; incomes of the local } \\
\text { population; investments from the state, etc. }\end{array}$ \\
\hline $\begin{array}{l}\text { 3. Political attractiveness is the ability of } \\
\text { the territory to effectively carry out } \\
\text { activities related to the realization of the } \\
\text { interests of social groups }\end{array}$ & $\begin{array}{l}\text { legitimacy; } \\
\text { lobbyism; } \\
\text { loyalty of the local population, etc. }\end{array}$ \\
\hline $\begin{array}{l}\text { 4. Social attractiveness is ability Territories } \\
\text { to ensure a decent "standard of living" of } \\
\text { the local population }\end{array}$ & $\begin{array}{l}\text { a health system; education system; } \\
\text { urbanization, etc. }\end{array}$ \\
\hline $\begin{array}{l}\text { 5. Cultural appeal is an opportunity of } \\
\text { territories to create conditions for the } \\
\text { development of creativity of the local } \\
\text { population }\end{array}$ & $\begin{array}{l}\text { tolerance; } \\
\text { objects of cultural heritage; festivals, } \\
\text { contests, creative meetings, etc. }\end{array}$ \\
\hline $\begin{array}{l}\text { 6. Tourist attractiveness is the ability of a } \\
\text { territory to arouse interest from citizens } \\
\text { who are not local people, in order to satisfy } \\
\text { their health, educational, sports, religious } \\
\text { and other needs (destination). }\end{array}$ & $\begin{array}{l}\text { recreational resources; } \\
\text { attractions; } \\
\text { reserved objects, etc. }\end{array}$ \\
\hline $\begin{array}{l}\text { 7. Technological attractiveness - this is the } \\
\text { ability of the territory to quickly respond to } \\
\text { changes in scientific and technological } \\
\text { progress }\end{array}$ & $\begin{array}{l}\text { nanotechnology; } \\
\text { robotics; } \\
\text { energy-saving technologies, etc. }\end{array}$ \\
\hline $\begin{array}{l}\text { 8. Exceptional attractiveness is the unique } \\
\text { features of the territory that are inherent } \\
\text { only to it - natural phenomena }\end{array}$ & $\begin{array}{l}\text { folk crafts; } \\
\text { territory branding }\end{array}$ \\
\hline
\end{tabular}

Note: compiled by the authors based on [5-8].

In addition to the investment plane, there were questions in the study that allowed us to know about the attractiveness of the territory from the point of view of representatives of two more groups close to the considered one - creative class (4 questions), tourists (2 
questions). These groups have their own decision-making features that are quite rigidly formed in older people.

Students were selected for the survey as one of the most contact and accessible groups of the general target audience (population of the territory), while the research questions were formulated in a certain way. A target orientation to investment thinking was chosen, which would reflect the most rational approaches, and to a lesser extent, emotional motives. The opportunity to enter the role of investor is a challenge for many young people, and is able to reflect latent, insufficiently well-understood by society priorities that it makes sense to orient the city authorities in developing strategic planning documents, targeted investment programs. Also, the results of the study may be claimed by private investors.

Students, young people strive to take a position in the urban social environment, where interactions between different strata of society are intensified and communication mechanisms and tools are continuously improved. Dialogicity of the urban environment, sociocultural heterogeneity, intense intellectual life attract young people to megacities, setting the coordinates of their territorial mobility - from the periphery to the center, from conservative solutions to innovative ones.

R. Florida believes that social changes in modern society are largely due to the transformation of social actions and interactions of residents of large cities. The megalopolis becomes "a reservoir of creativity and a means of mobilizing it" [9], which creates the conditions for attracting young people into it as a potential high-resource group from which recruiting into the managerial, intellectual, and creative elite is possible in the future.

The megalopolis, as a special living environment, creates specific living conditions and new foundations for shaping the image of the city. In a super-integrated economic, social and political system of a megalopolis, on the one hand, resources and opportunities for their use are concentrated, on the other hand, the unity of territorial society is destroyed, a space of coexistence of people is constructed, characterized by a high degree of tension and saturated with conflicts (both latent and open) [10].

Powerful streams of information, people, goods, signs, samples and symbols pass through megacities, which gives rise to a new type of city, which M. Castells called "informational" [11]. The complicated and heterogeneous structure of its environment intensifies territorial mobility, "pushing out" some residents and "involving" new ones.

\section{Applied methodology, research materials}

In 2019, we conducted a standardized sociological survey of students of higher educational institutions of St. Petersburg, based on a polymetodic strategy. The survey involved 180 people studying in 3-4 undergraduate and graduate programs at different faculties in three large universities: St. Petersburg State University, St. Petersburg State University of Economics, St. Petersburg State Polytechnic University named after P. the Great. The composition of the respondents included 82 young men and 98 girls aged 20-25 years, who mastered programs in various areas and specialties: $32 \%$ for technical and natural sciences, $26 \%$ for humanitarian, $42 \%$ for socio-economic. For $37 \%$ of the subjects, St. Petersburg was the place of birth and permanent residence; $63 \%$ came here from other settlements (for $84 \%$ of them, this relocation is associated with admission to a higher educational institution).

Information was collected by the method of distributing full-time questionnaires at the place of study of students. The author's questionnaire included 16 questions, including 6 closed, suggesting the choice of one or more answer options, and 10 open, to which the subjects answered in a free form, expressing their opinions and expressing their own 
associations. The data obtained were processed using the SPSS statistical analysis package (version 20).

A series of in-depth interviews $(n=10)$ was also organized, the main purpose of which was to study students' investment plans. The guide (form) of the interview consisted of 14 basic questions, the average interview lasted 30 minutes. Taking into account the orientation of students on personal investment experience and investment estimates, 5 girls and 5 young men aged 22-24 years who participated in the quantitative stage of the study were chosen as informants. Processing the collected materials using the method of thematic networks [12] made it possible to single out the main topics in the interview texts and group them by key fragments and ranking with the definition of a system of links between thematic blocks.

Questions were asked based on the current and future attractiveness of the territory for doing business. Of the respondents, 12 people own this or that business (7\%), have experience in managing the business as a proxy (usually parents or close relatives) - another 17 people. Thus, $16 \%$ of respondents have managerial experience, $73 \%$ reported that they have experience in evaluating investment and managerial decisions as employees, as well as for training purposes, $11 \%$ admitted that they have no direct and / or evaluative experience in investing. For this category of students, the block of questions devoted to making decisions about life in a metropolis on a long-term basis was of particular importance.

Among the respondents, they have experience in making investment decisions in the following types of business: retail outlet or their network (street coffee stall) - $2 \%$, rental apartments $-2 \%$, beauty salon or hairdresser $-1.5 \%$, car wash $-1,5 \%$, hostel $-1.5 \%$, business in the IT sector $-1 \%$, other $-4.5 \%$. As part of the study, students were also asked to assess the potential willingness to invest in the future as owners or managers of enterprises.

\section{Results}

As part of the study, the students 'investment strategies were studied within the framework of the attractiveness of the city's infrastructure facilities, the characteristics of which were assessed from the point of view of the respondents as suitable / not suitable in order to connect their own life with the city and make investments here in the future. It was proposed to evaluate the investment priorities and investment potential of various infrastructure facilities of the city and aspects of its life. A quantitative presentation of the results is based on the processing of the most common answers in open questions, and their interpretation is based on interview materials.

As part of the study of the attractiveness of transport infrastructure, the following results were obtained (Fig. 1).

Most students use public transport, which is why investments are encouraged, first of all, in projects related to improving the convenience of movement in underground and ground public transport, including greater freedom of cycling.

Students noted that in the future, as part of ensuring transport accessibility of the St. Petersburg suburban campus project, the advantages of the ring railway will be in demand. The appearance of dedicated bike lanes in the city in recent years is assessed positively, most of the respondents believe that it is advisable to continue investing in the development of bicycle traffic.

The developed public transport system (including the metro) and the road network make it possible to solve one of the most pressing problems - accessibility and freedom of intracity movements. From the perspective of students, investment in transport is very 
important for the city, as transport communication becomes a resource of everyday mobility, ensuring the dynamism and reliability of maintaining the rhythm of everyday life.

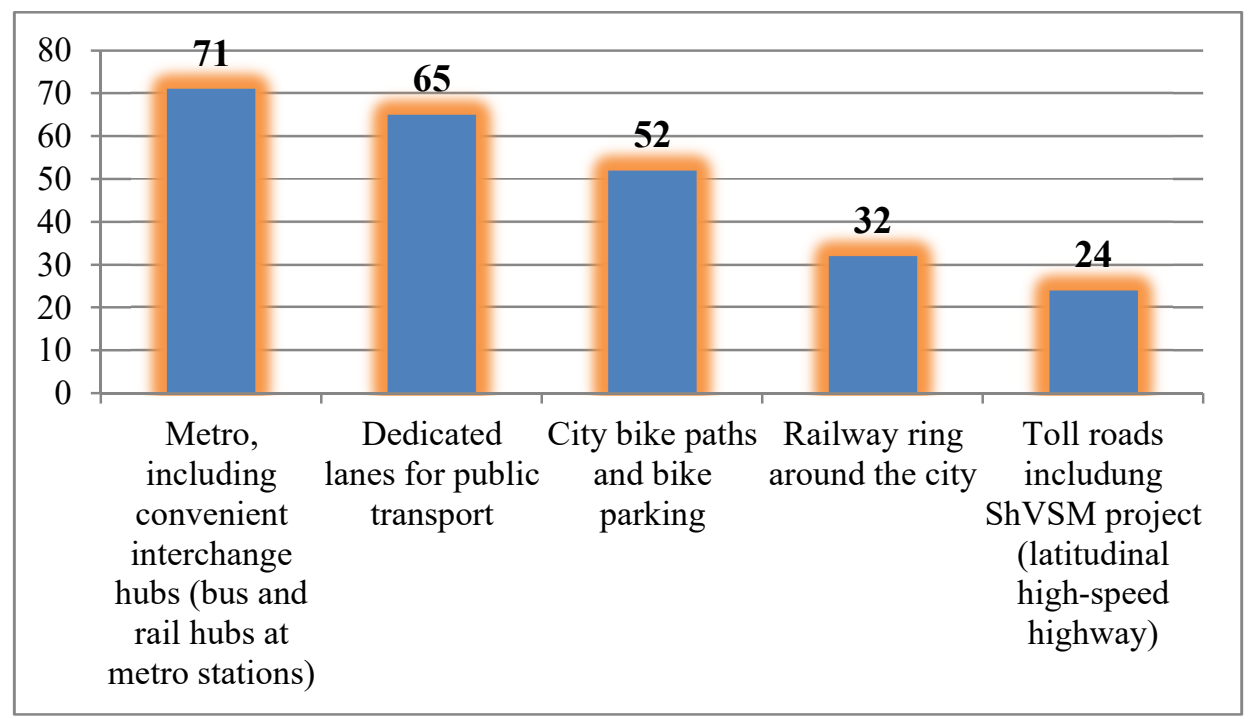

Fig.1. Urban transport facilities of St. Petersburg, which, according to students, require investment in development, \%

Assessment of the investment potential of urban improvement elements yielded the following results (Fig. 2).

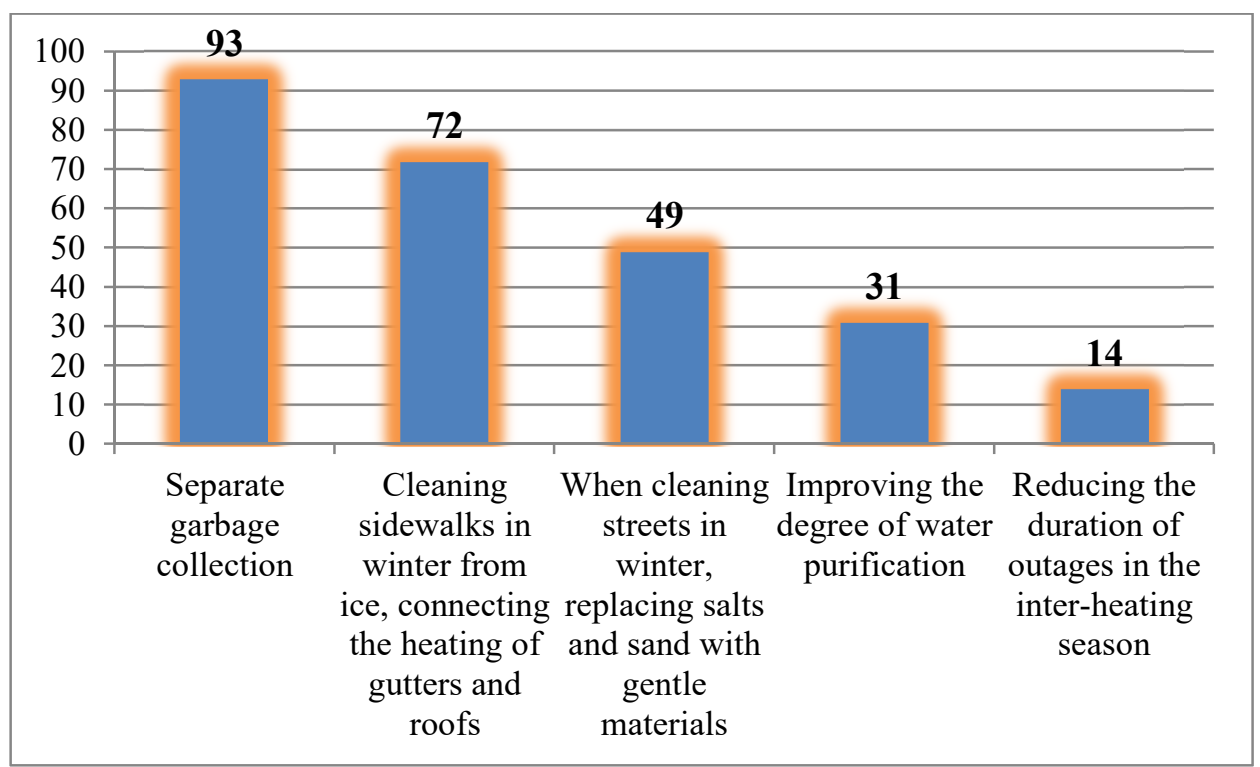

Fig. 2. Elements of urban improvement in St. Petersburg, which, according to students, require investment in development, $\%$

In the urban economy, the most popular, according to respondents, is a systemic transition to separate waste collection. Investments are required in the system of anti-frost and winter street cleaning, in a number of other elements of urban improvement - especially in the historic center, where a special environment is taking shape. 
The development of territories through the reorganization of the historical environment unites a large number of people and social groups in a common concept of life and contributes to the advanced organization of urban planning through the manifestations of "biosphere thinking" [13]. "Biosphere" thinking requires restructuring the prevailing antagonistic attitude of the urban population to the natural environment as a place for the extraction of resources, characteristic of the raw material type of economy and production relations. The rational use of natural resources and their replacement with renewable energy sources, production and reproduction of natural components in urban life are interconnected [13].

The results of the survey indicate the willingness of young people to direct efforts and investments in a number of priority socially significant projects related to the application of an ecological approach to the formation of an urban environment.

In the study of investment priorities of urban recreation areas, the following results were obtained (Fig. 3).

According to the results, the presence of park areas in the metropolis is of great importance for students, which are not only an environmental factor and a visual background (green space positively affects both the mental and physical health of citizens), but also bear an emotional, personal, associative load - they become certain semantic points, places of significant and pleasant events - dates, talking with friends, walking, playing sports, etc. [10]. Garden and park ensembles, as well as the preservation of natural landscapes, the beauty of nature reserves, was assessed as an important investment direction in creating a comfortable environment for city residents to relax.

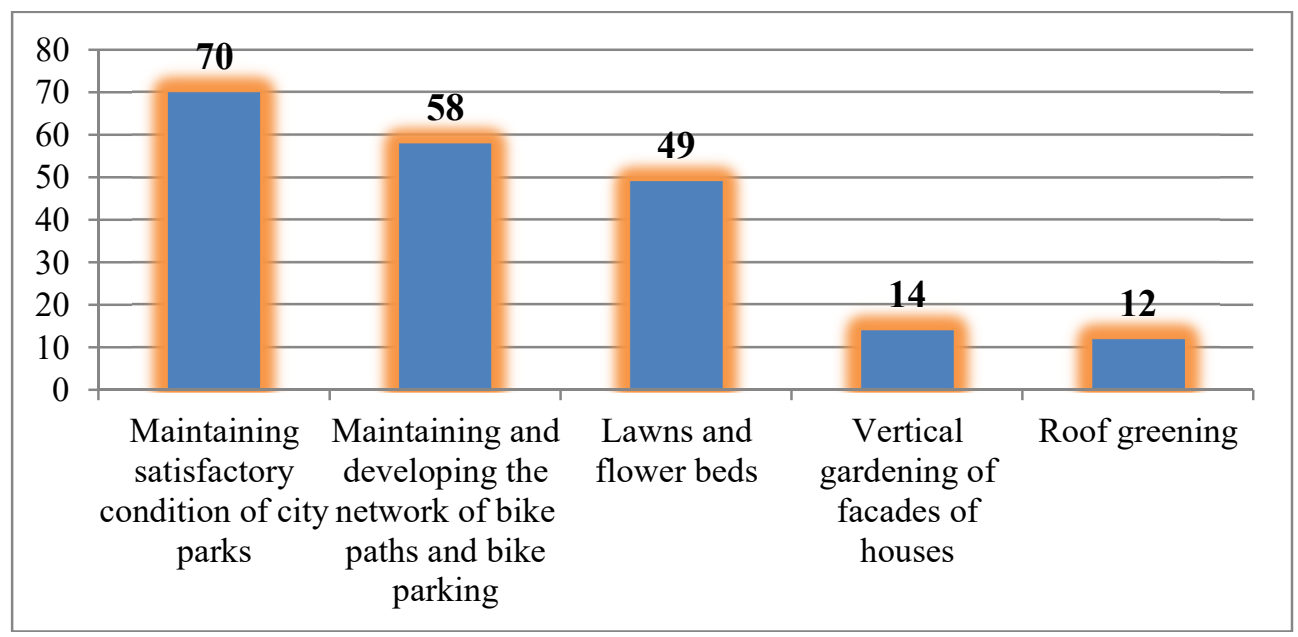

Fig. 3. Elements of urban recreation areas of St. Petersburg, which, according to students, require investment in development, \%

Cycle paths have again been identified as one of the desired investment areas along with parks and landscaping. In addition, it should be noted that students consider such elements of modern improvement as landscaping of facades and roofs important.

Currently, landscaping of roofs and facades of houses is actively carried out in Europe Scandinavia, Germany and others. This trend is associated with an ecological approach to the formation of an urban environment, which is increasingly in demand not only in the construction of new buildings, but in the renewal of historical quarters [14].

Assessment of investment opportunities in relation to urban cultural, art and patriotism objects showed the following results (Fig. 4). 


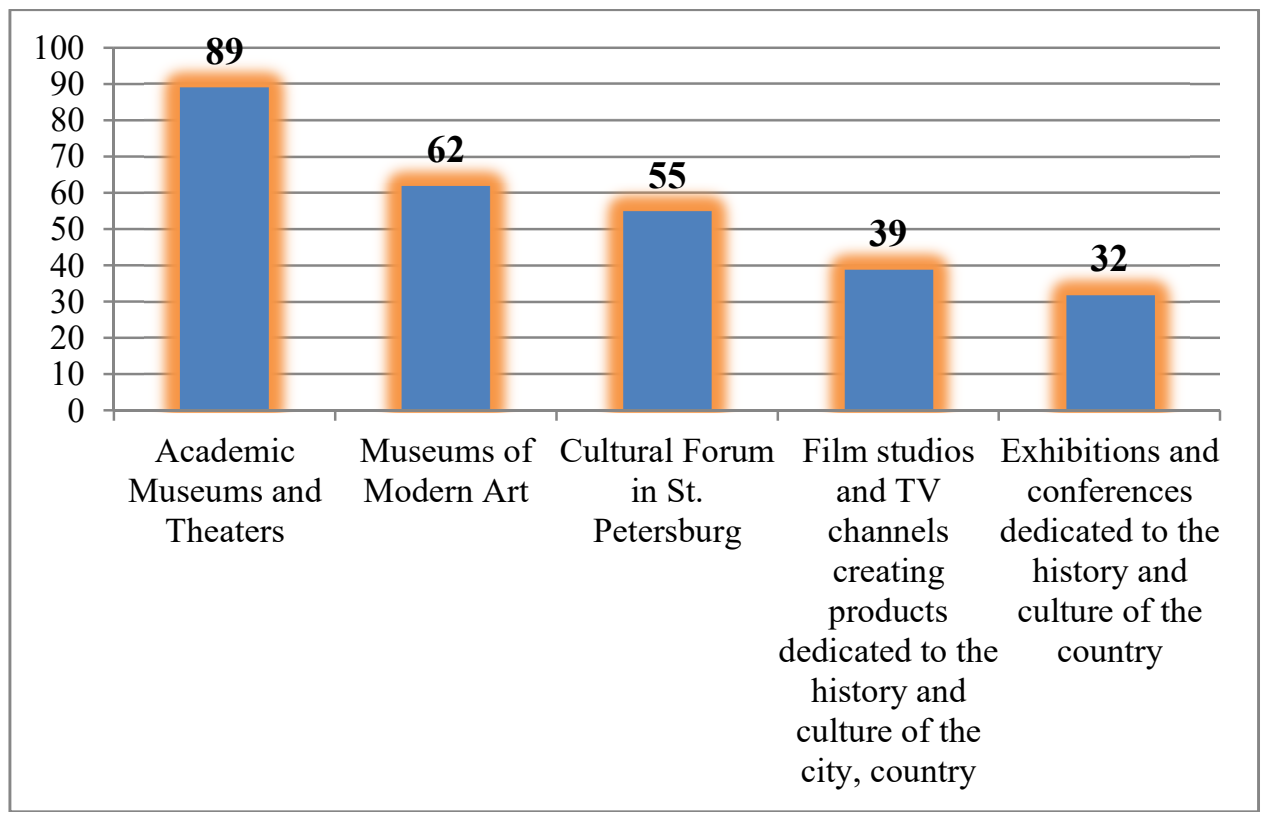

Fig. 4. Objects of culture, history and patriotism in the of city, the most promising for investment, according to students, $\%$

Academic (traditional) cultural and art institutions have the greatest investment potential, similar to projects to expand the Hermitage's activities at the General Staff site, but there is also an attractiveness for further investment in contemporary art museums in the city, including private ones (Erarta, Artmuza, New Holland and others). Students noted the importance of the Cultural Forum, held annually in the city for the past 7 years, as well as other events dedicated to the history and culture of the city and country.

$t$ should be noted that an intensive cultural life is directly related to the expansion of the so-called creative economy, which students consider one of the most promising investment areas. Creative industries today are industries involving the creation of analog or digital products and services, which are based on a creative approach, individual talent and professional skills of an author or team

As noted, cultural and creative industries are key drivers of economies in developed and developing countries. They affect revenue generation, job creation and export earnings. The capitalization of enterprises of the creative economy in the world is estimated at $\$ 2.250$ trillion. The "Big Three" of creative industries by income include: television (\$ 477 billion), visual art (\$391 billion), media - newspapers and magazines (\$ 354 billion). Creative industries created over 30 million jobs worldwide ( $1 \%$ of the working population), including: visual art (6.73 million jobs), books (3.67 million jobs), music (3.98 million jobs) [15].

The definition of representatives of the creative class proceeds from two approaches: belonging to a specific set of creative industries (narrow definition) and the use of a knowledge-intensive approach in activities (a broader definition that allows expanding the assessment of the size of the creative economy). If from the point of view of the first approach about $1 \%$ of the able-bodied population is attributed to the creative class, then another approach to the definition of the creative class is based on the knowledge of the intensive nature of its activity. From this point of view, up to a third (29\%) of the ablebodied population belongs to the creative class [16]. 
The respondents consider the involvement of the creative class and the reproduction of "knowledge workers" at the expense of graduate students to be the most important factor in the development of the city. Modern studies also indicate the need to compare the socioeconomic and other characteristics of the regions, to take into account the degree of territorial attractiveness and creative attractiveness of the city as factors that determine students' life plans [17].

As an important characteristic of the image of the city, the respondents, in addition to cultural objects, pointed to the high attractiveness for investment of objects related to sports, leisure and entertainment (Fig. 5, 6).

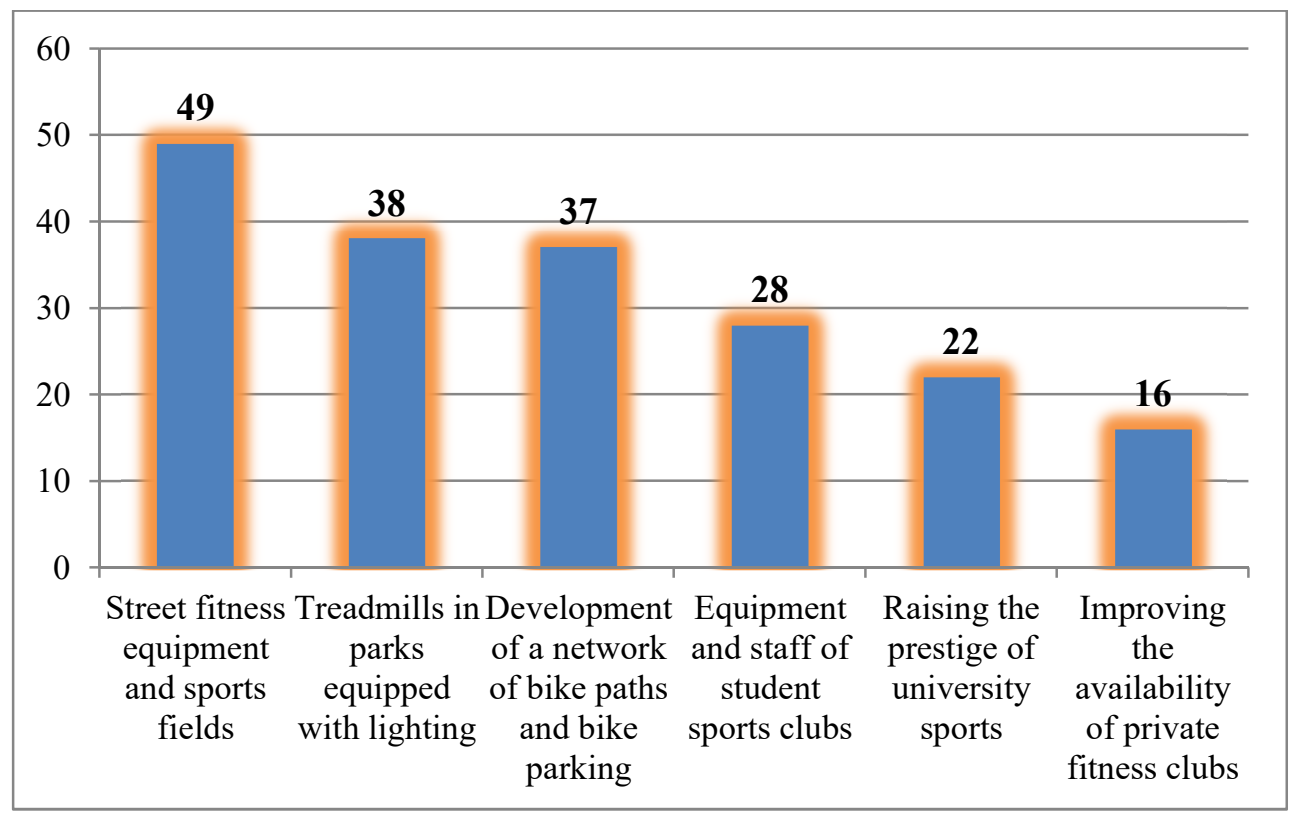

Fig. 5. Sports facilities of St. Petersburg, which, according to students, require investment in development, \%

With regard to sports facilities, the preferred direction of investment in sports facilities free of charge for users has been identified - street exercise machines, lighting of running zones in parks, expansion of the network of bike paths. Particular attention is paid to student sports, in particular investments in the equipment of student sports clubs and in university sports competitions, taking into account modern requirements for the level of organization of these events, sports management and marketing.

Only about $1 / 6$ of the respondents indicated the need for subsidies or other forms of support for students, which would increase the availability of regular commercial fitness clubs. Thus, most students prefer street sports, and the price level for fitness club memberships does not seem overstated for most.

In relation to other leisure facilities in the city, investment preferences were clarified indirectly (Fig. 6). 


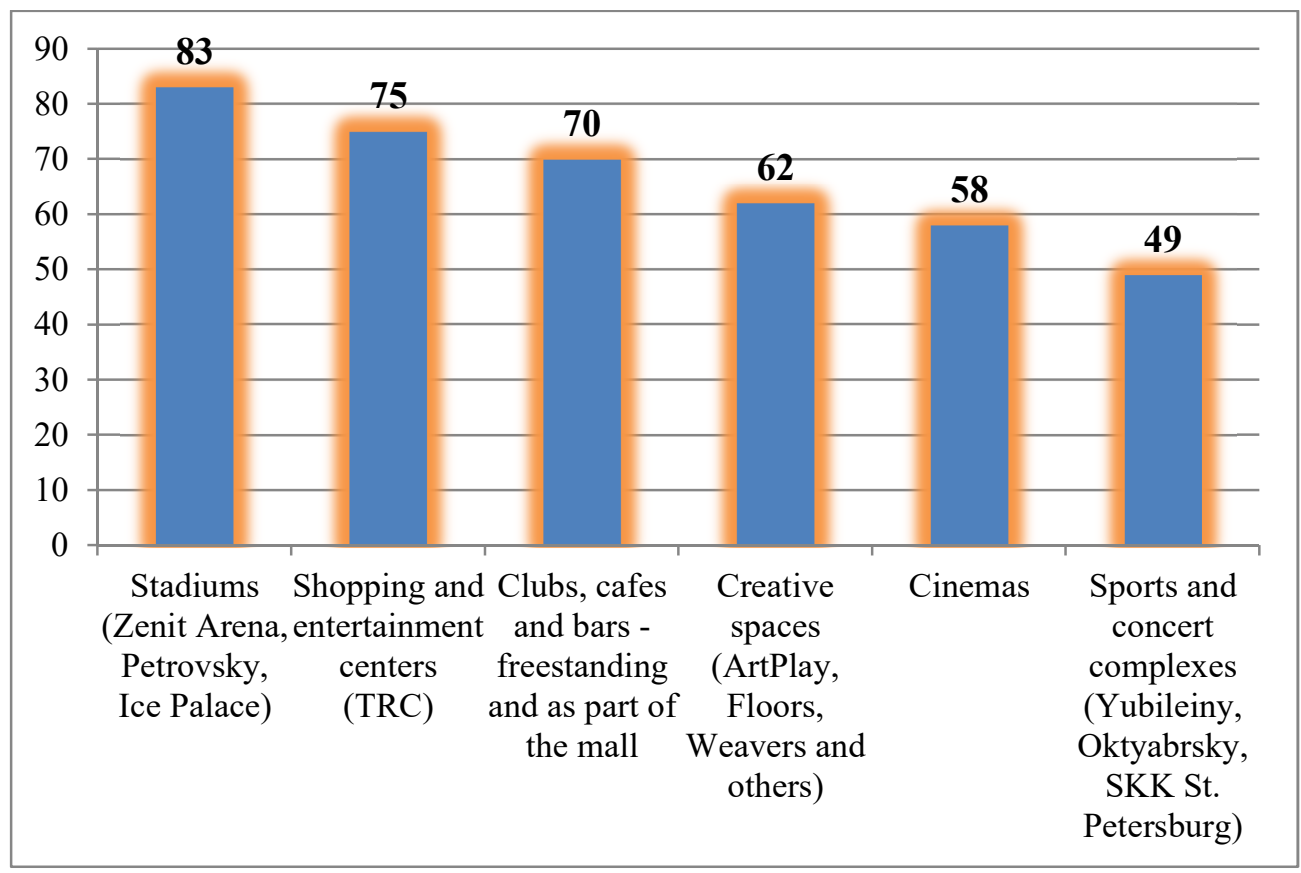

Fig. 6. Leisure facilities in St. Petersburg, which, according to students, provide high quality services, $\%$

Initially, students' satisfaction with the current level of service in existing facilities of mass leisure was revealed. Most students experienced the greatest satisfaction (positive marks) from visiting the Zenit-Arena stadium, the construction of which for a long time remained in the center of attention of citizens. Other entertainment leisure facilities are also generally recognized as satisfactory and do not require additional investment, including the current SKK "St. Petersburg”. The appearance of a new building for spectacular leisure, the Igora-Drive high-speed race track in the Leningrad Region, was noted.

Significant attention in relation to other leisure facilities was paid to the activities of shopping and entertainment centers. Indeed, modern shopping and entertainment centers (SECs, malls) provide various opportunities for the implementation of many functional areas of leisure - sports, children, socializing - communicative, gastronomic, etc. Shopping centers include stores with branded clothing / shoes and branded cafes and restaurants forming a sense of ownership of the global fashion trends and serving as markers of globalization processes, the inclusion of the metropolis in the global communication space.

At the same time, clubs and bars located both in shopping centers and associated with them, and separately standing, according to some researchers, for some youth strata become the "third place" in terms of life in the social space of the city after the house - "number one" - and works - "numbers of the second" [18].

In this regard, we note that from the point of view of the basic features of public spaces (accessibility, openness for all), shopping and entertainment centers are quasi-public spaces, since the dominance of monetary consumer practices limits the possibility and comfort of insolvent groups in the population. The commercialization of public spaces turns the principle of universal accessibility into the principle of limited accessibility for a number of target consumer groups [19]. Such types of public spaces as shopping centers, cafes, restaurants, amusement parks and amusement parks have selective accessibility, segmenting city residents by the possibilities of paying for the consumption of a number of goods and services. 
Nevertheless, due to the transfer of responsibilities for servicing such spaces to the private sector, the attractiveness of the corresponding territory as a whole increases. A business operating in a fiercely competitive environment is forced to focus on achieving maximum satisfaction among urban users. In addition, the high dynamism of the life of modern cities stimulates the emergence of fundamentally new types of public spaces both in terms of technological solutions and in terms of their social content (targeting various kinds of public and various forms of public activity).

There is a growing demand for creative, modular spaces, transforming spaces, combining shops, offices, creative studios, master classes, exhibitions, event venues, etc. [20]. In recent years, so-called creative spaces (New Holland, Weavers, ArtPlay, Floors and others) have also been actively developing in St. Petersburg. It is they who have recently most often become demonstration sites, places for city competitions, expositions and fairs.

The technical, aesthetic, eventful arrangement of both shopping and entertainment and creative spaces ultimately contributes to the harmonization of urban everyday life and stimulates the growth of positive social effects from investments in the urban environment the creation of a friendly atmosphere and communications, the exchange of diverse social experiences [21, 22].

In general, we can conclude that according to students, the current level of service provision by the most significant leisure facilities in the city is satisfactory, and they do not require significant investments. Opinions regarding the reconstruction project of the SKK "St. Petersburg" were divided. For many respondents, the benefits of a new construction project in this territory, announced by the authorities and the developer in 2019, are not obvious.

At the end of the study, the respondents were asked to name those leisure facilities that the city lacks, or they are of unsatisfactory quality, and therefore public or private investments in new construction or reconstruction are appropriate (Fig. 7).

Most students considered it necessary to make public investments in the reconstruction of the zoo (creating a new one). Those students who considered private investment options mostly talked about new concepts of clubs and creative spaces created by private business. Projects related to multi-story high-rise buildings (skyscrapers) received somewhat lower, but significant estimates among promising investment objects. Apparently, the "high-rise" projects indicated by the respondents are based on expectations from the completion of the Lakhta Center, which would incorporate a number of technological innovations and implement a set of modern leisure concepts.

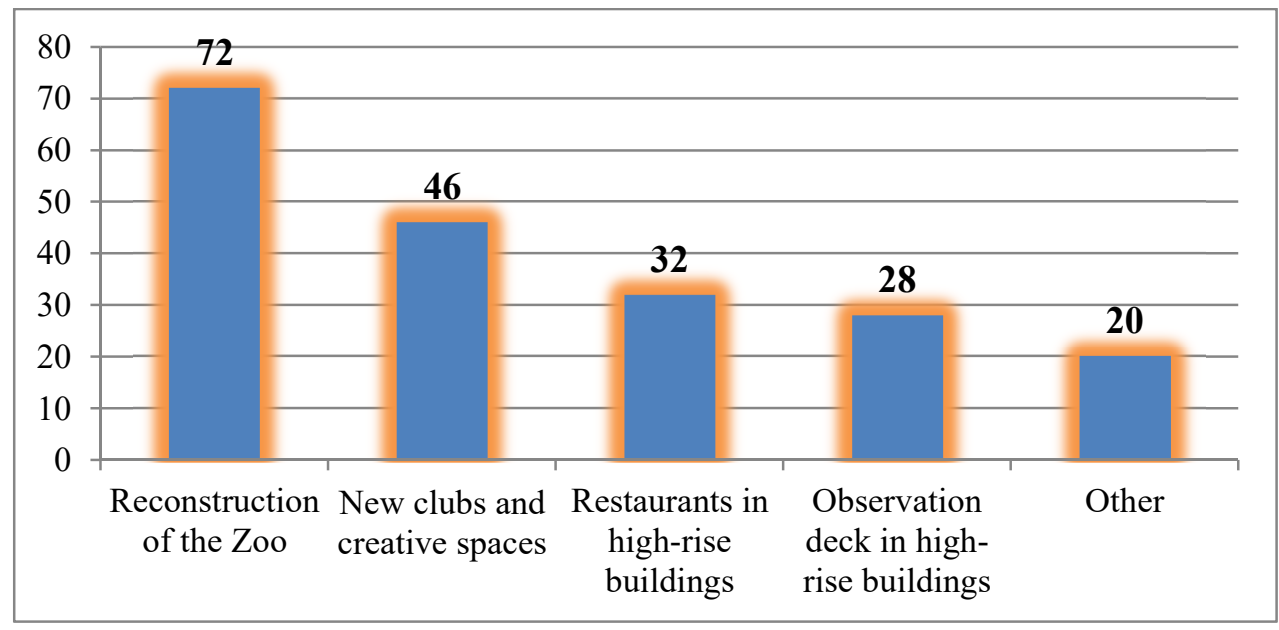

Fig. 7. Priority investment objects of leisure in St. Petersburg, according to students, \%. 
All other ideas of investing in leisure facilities of the respondents were of a singular nature, in connection with which the authors decided to analyze the features of those investment areas, which, according to students, will be promising for private business and associated with the operation of high-rise buildings, including Lakhta Center.

Lakhta Center is a project of a technologically innovative, public and business complex in the Primorsky district of St. Petersburg, on the shores of the Gulf of Finland. The initiator of the construction is Gazprom Neft. Work on the building frame continued from August 2013 to June 2018. In 2019, interior decoration continues. The architectural structure was designed as the highest building in Russia and Europe, the height of the skyscraper is 462 meters.

At the same time, less than half, namely $45 \%$ of all Lakhta Center areas are reserved for office premises. The rest is public space, which claims to be the point of attraction of citizens and tourists. The main elements of the public space of the complex will be: observation deck; panoramic restaurant; planetarium, historical frigate Poltava, maritime museum and yacht club, which are 300 meters from the complex and have been operating since 2018; co-working center; sports cComplex; atrium (transformer hall); open amphitheater. (tab. 2).

Table 2. Elements of the public space of the Lakhta Center and their significance

\begin{tabular}{|l|c|c|c|}
\hline \multirow{2}{*}{$\begin{array}{c}\text { Elements of the public } \\
\text { space of the complex }\end{array}$} & \multicolumn{2}{|c|}{ Number of visitors } & \multirow{2}{*}{ Main facts } \\
\cline { 2 - 3 } & $\mathbf{2 0 2 0}$ & $\begin{array}{c}\mathbf{2 0 2 4} \\
\text { plan }\end{array}$ & \\
\hline $\begin{array}{l}\text { 1. The total number of } \\
\text { visitors, including (in } \\
\text { thousand): }\end{array}$ & 2 & 3 & 4 \\
\hline Observation deck & 525,00 & 551,90 & Visitors: $15 \%$ - residents, $85 \%$ - tourists \\
\hline Panoramic restaurant & 18,00 & 130,00 & $\begin{array}{c}\text { The opening of most elements of the } \\
\text { public space is planned for } 2020 \\
\text { Lakhta Center; } 40 \% \text { - city residents, } 50 \% \text { - } \\
\text { tourists }\end{array}$ \\
\hline Frigate "Poltava" & 103,02 & 107,20 & $\begin{array}{c}\text { For those interested in navigation and the } \\
\text { history of shipbuilding }\end{array}$ \\
\hline Planetarium & 15,00 & 89,14 & $\begin{array}{c}\text { The third planetarium in the city fills this } \\
\text { segment of leisure preferences of the } \\
\text { population }\end{array}$ \\
\hline $\begin{array}{l}\text { Events of the open } \\
\text { amphitheater, atrium }\end{array}$ & 25,00 & 37,14 & $\begin{array}{c}\text { An open-air concert venue and a modern } \\
\text { lecture space }\end{array}$ \\
\hline Co-working center & 2,00 & 4,00 & Promising creative class incubator \\
\hline $\begin{array}{l}\text { Sports club, children's } \\
\text { clubs and other facilities }\end{array}$ & 50,00 & 50,00 & $\begin{array}{c}\text { Allows you to integrate the complex into } \\
\text { the social infrastructure of the Primorsky } \\
\text { district of the city }\end{array}$ \\
\hline
\end{tabular}

Note: tab. 2 compiled by the authors based on press materials.

Thanks to the coworking center, a new creative cluster is expected to form in the Lakhta Center area. The possibilities of an open amphitheater, atrium rooms, as well as co-working allow you to:

- holding various music festivals of modern and classical music, film screenings, art exhibitions and staging of a modern theater in the vast territory of the complex. It is supposed to use the summer season, as open-air events always turn out to be more successful and vibrant (an example of New Holland); 
- conducting educational, art lectures. The Lakhta Center, supporting the current information agenda (ecology, feminism, IT technologies, contemporary art, etc.) will stand out from other cultural centers and lofts due to large-scale spatial capabilities and the "cyberpunk" aesthetics of the complex;

- the work of children's clubs and development centers;

- creating an attractive workspace.

The abovementioned leisure and "creative" opportunities of Lakhta Center in many respects reflect those investment priorities that the respondents indicated as promising for private investments.

\section{Discussion}

It should be noted that during the interview, the interlocutors pointed to the high level of saturation of the city with cultural events (mass citywide festivals and festivals, exhibitions of national and world level, master classes, sports events held in well-equipped facilities, etc.), as well as wide opportunities currently available for the self-development of youth in the city. Within the framework of the available assessments of the attractiveness levels of Russian cities [23], the indicators achieved by St. Petersburg are outstanding among large cities in Russia. However, the achievement of values of indicators of the comfort of living, gardening, caring for the environment, comparable with those of industrialized countries, requires further investment and significant organizational efforts of the city authorities. The directions of these efforts must be verified with the preferences of different age and professional strata.

\section{Conclusion}

In the framework of the study, the investment priorities and investment potential of various objects of the city's infrastructure and aspects of its life were evaluated as follows:

- transport investments are associated with improving the convenience of movement in underground and ground public transport, including ensuring greater freedom of cycling.

- in the urban economy, the principles of environmental management are expressed in the expectation of investments in separate waste collection, the highest priority, according to the respondents, in comparison with other elements of urban improvement;

- when researching the investment priorities of urban recreation areas, one of the desired investment areas, along with parks and landscaping, is the expansion of the network of bike paths and bike parking;

- an assessment of investment opportunities in relation to urban cultural objects and the development of patriotism showed the priority of academic (traditional) cultural and art institutions and the expansion of the scope of the creative economy;

- in relation to sports facilities, the preferred direction of investments in sports facilities free of charge for users has been identified - street exercise machines, lighting of running zones in parks, bicycle paths, which, as outdoor sports facilities, are accessible to most citizens.

- investment preferences of the majority of respondents regarding leisure facilities are related to the implementation of new concepts of clubs, creative spaces, bars, including iconic places in high-rise buildings, as well as providing the possibility of public investment in the reconstruction of the zoo. 


\section{References}

1. E.I. Tsaregorodtsev, M.V. Sairanova, The economic potential of the development of socio-economic systems of the region (2015)

2. A. Gurko, S. Oparina, L. Vasyutkina, E. Potekhina, E3S 91, 08029 (2019) doi: 10.1051 / e3sconf / 20199108029

3. D. Radushinsky, A. Radushinskaya, I. Radikov, O, Feoktistova, A. Butyrin, MATEC, 35, 01043 (2018) doi: 10.1051 / matecconf / 201817001043

4. A.V. Bataev, A.A. Gorovoy, A.B. Mottaeva, IBIMA 2018, 102-114 (2018)

5. S. Parnell, Defining a Global Urban Development Agenda, 78, 529-540 (2016).

6. E. Smirnova, V. Zaikin, E3S, 91, 05030 (2019) doi: 10.1051 / e3sconf / 20199105030

7. H. Bulkeley, Cities and Climate Change (2013)

8. S. Sergeev, T. Kirillova, I. Krasyuk, E3S, 91, 05007 (2019) doi: 10.1051 / e3sconf / 20199105007

9. R. Florida, How the Creative Economy Is Making Where to Live the Most Important Decision of Your Life (2008)

10. P. Lawton, E. Murphy, D. Redmond, Residential preferences of the 'creative class', 31, 47-56 (2013) doi: 10.1016 / j.cities.2012.04.002.

11. K. Pina, B.S. Tether, Towards understanding variety in knowledge intensive business services by distinguishing their knowledge bases, 45 (2), 401-413 (2016) doi: 10.1016 / j.respol.2015.10.005

12. J. Attride Stirling, Thematic networks: an analytical tool for qualitative research, 3, 385-405 (2001) doi: 10.1177 / 146879410100100307.

13. H. Lefebvre, The production of space, (1991)

14. Green Roofs for Healthy Cities, 10 (2016).

15. C. De Beukelaer, K.-M. Spence, Global Cultural Economy (2019)

16 A.. Kirch, "Knowledge Workers" in the Baltic Sea Region: Comparative assessment of innovative performance of the countries in the macro-region, 8, 176-196 (2018) doi: 10.1515 / bjes-2018-0010.

17. F. Giambona, M. Porcu, I. Sulis, Students Mobility: Assessing the Determinants of Attractiveness Across Competing Territorial Areas, 3, 1105-1132 (2017) doi: 10.1007 / s11205-016-1407-one.

18. R. Oldenburg, Third place. Cafes, coffee houses, bookstores, bars, beauty salons and other places of "parties" as the foundation of the community (2014)

19. D. Radushinsky, A. Mottaeva, L. Andreeva, G. Dyakova Earth and Environmental Science, 90, 012137 (2017) doi :10.1088/1755-1315/90/1/012218

20. S. S. Wu, Events as community function of shopping centers: a case study of Hong Kong, Cities, 130-140 (2018) doi: 10.1016 / j.cities.2017.08.08.017

21. A.B. Antonova, A.I. Radushinskaya, O.A. Sharapova, Applying modern media technologies to preserve the cultural space of historical cities using the case of St. Petersburg: methodical approaches, Service in Russia and abroad, 7 (77), 17-31 (2017).

22. A. Mottaeva, E3S, 110, 02164, (2019) doi.org/10.1051/e3sconf /201911002164

23. V.V. Oreshnikov, M.M. Nizamutdinov, The forecast of changes in the level of attractiveness of Russian cities, Regional Economics: theory and practice 4 (463), 749-762 (2019) 